\title{
Phase Segregation of Crosslinked Polyurethane by Small Angle X-Ray Scattering
}

\author{
Tsang-Lang LIN, T. Leon Yu, ${ }^{* \dagger}$ Wen-Jiun LIU, and Yi-Ming TsaI* \\ Department of Engineering and System Science, National Tsing-Hua University, \\ Hsinchu 30043, Taiwan, R.O.C. \\ * Department of Chemical Engineering, Yuan-Ze University, Taoyuan, Nei-Li 32026, Taiwan, R.O.C.
}

(Received January 12, 1998)

\begin{abstract}
Polyester based polyurethanes were synthesized from a low molecular weight polyester $\left(M_{n} \sim 2000\right)$ and 4,4'-methylene bis(phenyl isocyanate) (MDI) with butanediol as a chain extender and glycerol as crosslinker. The polyester was synthesized from adipic acid and glycol, a mixture of 1,6-hexanediol and 1,2-propanediol. The effect of the crosslinker content on the phase segregation of soft- and hard-segments was studied by DSC (differential scanning calorimetry) and SAXS (small angle X-ray scattering). The introducing of triol functional group into the hard segments increased the aggregation of hard segments through crosslink covalent bonds. Owing to highly steric hindrance, the presence of tri-ol crosslinker in the hard segments decreased the aggregation of hard segments through hydrogen bonding. The phase segregation of soft- and hard- segments is thus due to the aggregation of hard-segments through crosslinked covalent bonds and $\mathrm{H}$-bonding.

KEY WORDS Polyurethane / Differential Scanning Calorimetry / Small Angle X-Ray Scattering /
\end{abstract}

Segmented polyurethanes are thermoplastic elastomers which consist of hard and soft segment units. They are thermoplastic elastomers with a wide range of mechanical properties depending on the number of two structural components. It is generally agreed that the unique mechanical properties of polyurethanes, as compared to other types of elastomers, are predominantly the result of a two-phase morphology. ${ }^{1,2}$

Polyester based urethanes consist of an aromatic diisocyanate with a glycol chain extender as the hard segment and low molecular weight polyester as the soft segment. They are considered segmented block copolymers, made up of alternating hard and soft block segments. Compositional variables and processing conditions affect the degree of phase segregation, phase mixing, hard segment domain organization, and subsequent polyurethane properties. ${ }^{2-4}$ Depending on relative incompatibility of hard and soft segments, phase segregation occurs during processing and post cure annealing. The effects of polyurethane composition and structure on properties have been investigated, with attention to model compounds based on aromatic diisocyanates, such as toluene diisocyanate (TDI $)^{5,6}$ or diphenyl methane diisocyanate (MDI). ${ }^{5-8}$ The phase segregation of hard and soft segment domains has been demonstrated by: small and wide angle X-ray scattering, ${ }^{9-20}$ differential scanning calorimetry, ${ }^{9-18,21-24}$ infrared spectroscopy, ${ }^{24-29}$ microscopy, ${ }^{16,30,31}$ small angle laser light scattering (SALS), ${ }^{16}$ and dynamic mechanical thermal analysis (DMTA). ${ }^{18}$

In the present work, soft segment polyester-diols were synthesized from adipic acid and mixed glycols of 1,2-propanediol and 1,6-hexanediol. The polyurethanes were synthesized from polyester and 4,4'-methylene bis(phenyl isocyanate) (MDI) with mixtures of glycerol and 1,4-butanediol as a crosslinking agent and chain extender, respectively. The effect of the concentration of glycerol on the morphology of polyurethanes was studied

\footnotetext{
† To whom correspondence should be addressed.
}

by differential scanning calorimetry (DSC) and small angle X-ray scattering (SAXS).

\section{EXPERIMENTAL}

\section{Polyester-Diol}

Polyester-diol was synthesized using a conventional method from 1,2-propanediol, 1,6-hexanediol, and adipic acid (Riedel-de Haen Co.) with an $\mathrm{OH} / \mathrm{COOH}$ mole ratio of $1.18 / 1$ under nitrogen atmosphere. The mole ratio of monomer feed in the polyester polymerization was adipic acid/1,2-propanediol/1,6-hexanediol = $1 / 0.728 / 0.452$. 1,2-Propanediol was first reacted with adipic acid. The reaction temperature was increased by stepwise control as following: $140^{\circ} \mathrm{C} / 1 \mathrm{~h}, 150^{\circ} \mathrm{C} / 1 \mathrm{~h}$, $160^{\circ} \mathrm{C} / 1 \mathrm{~h}$, and $170^{\circ} \mathrm{C} / 1 \mathrm{~h}$. The reaction mixture was cooled to $90^{\circ} \mathrm{C}$ and mixed with 1,6-hexanediol. After mixing, the reaction temperature was increased to $150^{\circ} \mathrm{C}$ as follows: $150 / 1 \mathrm{~h}, 160^{\circ} \mathrm{C} / 2 \mathrm{~h}, 180^{\circ} \mathrm{C} / 2 \mathrm{~h}$, and $200^{\circ} \mathrm{C} / 4 \mathrm{~h}$. The acid value of the final polyester was $4.1 \mathrm{mg} \mathrm{KOH} \mathrm{g}^{-1}$ (determined by a method of ASTM D4662) and the $-\mathrm{OH}$ value was $62.9 \mathrm{mg} \mathrm{KOH} \mathrm{g}^{-1}$ (determined by a method of ASTM D4274). Thus, primary - OH terminal ends were present in the prepared polyester. The molecular weight distribution was determined by GPC (Waters model 746 with $\mu$-styragel columns of pore sizes of $500 \AA$, $10^{3} \AA$, and $10^{4} \AA$, and a RI detector) at $25^{\circ} \mathrm{C}$. Tetrahydrofuran (THF, Merck Co.) was used as the mobile phase, and narrow molecular weight distribution (MWD) polystyrene standards (Aldrich Chemical Co.) were used in a linear calibration. The $M_{n}$ and $M_{w} / M_{n}$ of the present polyester are 1800 and 1.8 , respectively.

\section{Polyurethane}

A polyester-diol was used to synthesize polyurethanes with MDI (98 wt\% purity, Tokyo Kasei Kogyo Co.), 1,4-butanediol (Riedel-de Haen Co.) as chain extender and glycerol (Reidel-de Haen Co.) as crosslinking agent by prepolymerization method. The chemical compositions of these polyurethanes are shown in Table I. These 
Table I. Chemical compositions of polyurethanes

\begin{tabular}{|c|c|c|c|c|}
\hline \multirow{2}{*}{ Polyurethane } & Polyester & MDI & Butanediol & Glycerol \\
\hline & mol & mol & mol & $\mathrm{mol}$ \\
\hline PU-1 & 1.0 & 5.61 & 3.88 & - \\
\hline PU-2 & 1.0 & 5.61 & 3.70 & 0.122 \\
\hline PU-3 & 1.0 & 5.61 & 3.51 & 0.244 \\
\hline PU-4 & 1.0 & 5.61 & 3.33 & 0.366 \\
\hline PU-5 & 1.0 & 5.61 & 3.15 & 0.488 \\
\hline
\end{tabular}

polyurethanes thus consist of polyester soft segments with various concentrations of crosslinking agent. Polyester-diol was first reacted with MDI at $90-100^{\circ} \mathrm{C}$ for $1 \mathrm{~h}$, and then with a mixture of 1,4-butanediol and glycerol at room temperature for $15 \mathrm{~min}$. The polymer was compression molded on a press at $175^{\circ} \mathrm{C}$ for $15 \mathrm{~min}$ followed by cooling at an ambient temperature. The samples were kept at room temperature for at least one week before DSC and SAXS measurements. Before polymerization, the polyester was dried at $90^{\circ} \mathrm{C}$ under vacuum for $2 \mathrm{~h}$ to remove moisture. 1,4-Butanediol and glycerol were treated with molecular sieve (Merck, pore size $0.4 \mathrm{~nm}$ ) drying agent. MDI was used as received without further purification. The final polyurethanes contained $\sim 51 \mathrm{wt} \%$ of polyester soft segment.

\section{Differential Scanning Calorimetry (DSC)}

DSC measurements were carried out on a DuPont 910 DSC. The heating rate was $10^{\circ} \mathrm{Cmin}^{-1}$ for the temperature range of $-100-240^{\circ} \mathrm{C}$. The samples' sizes were around $10 \mathrm{mg}$ for all measurements.

\section{Small Angle X-Ray Scattering (SAXS)}

Small angle $X$-ray scattering measurements were performed with a pinhole collimated X-ray camera, the radiation source of which is a Rigaku $18 \mathrm{~kW}$ rotating anode generator with $\mathrm{Cu}$ target, operated at $100 \mathrm{~mA}$ and $40 \mathrm{keV}$. A three pinhole system is used to collimate the $\mathrm{X}$-ray beams. Graphite is used to monochromatize the incident X-ray beams on the sample. The scattered intensity was detected by a two-dimension multi-wire detector (Oak Ridge Detector Laboratory, Inc.) with $256 \times 256$ channels for $20 \mathrm{~cm} \times 20 \mathrm{~cm}$ active area $(1 \mathrm{~mm}$ between each pixel). The sample to detector distance is $400 \mathrm{~cm}$ in length. All data were corrected for background (dark current) and sensitivity of each pixel in the area detector. For the amorphous system, the area of the scattered pattern was radially averaged to increase the efficiency of data collection as compared with onedimension linear detector.

\section{RESULTS AND DISCUSSION}

\section{DSC Study}

DSC curves of the five polyurethanes are shown in Figure 1. The positions of the DSC endotherms and thermal transitions are listed in Table II. The uncertainty associated with each temperature was approximately $\pm 2^{\circ} \mathrm{C}$. DSC thermal behavior was apparent in four temperature ranges.

The soft segment glass transition temperature $\left(T_{\mathrm{g} 1}\right)$ appears as a base line shift in the region of $-40--10^{\circ} \mathrm{C}$.

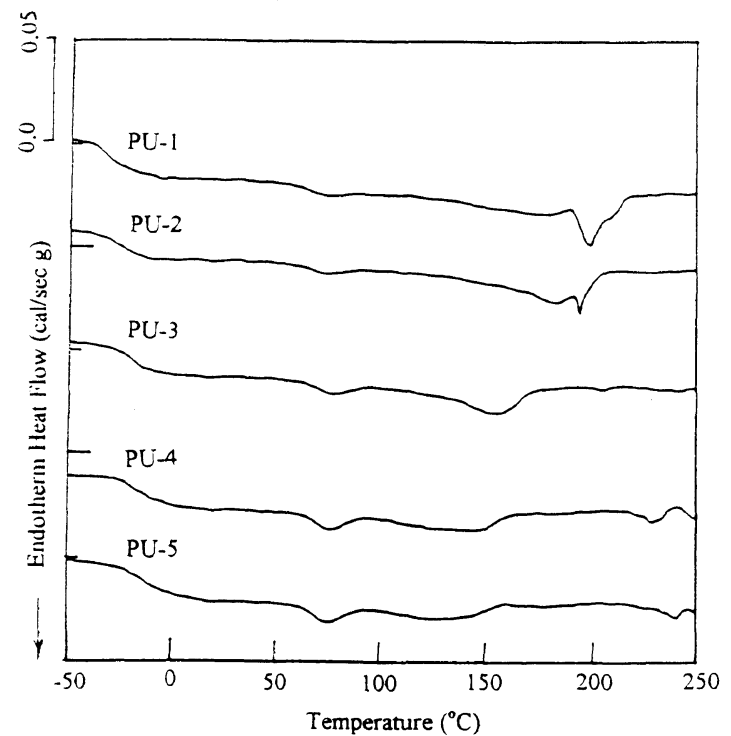

Figure 1. DSC curves of crosslinked polyurethanes.

Table II. DSC data of polyurethanes

\begin{tabular}{lccccc}
\hline Polyurethane & PU-1 & PU-2 & PU-3 & PU-4 & PU-5 \\
\hline$T_{\mathrm{g} 1} /{ }^{\circ} \mathrm{C}$ & -34.7 & -30.5 & -21.7 & -17.7 & -13.00 \\
$T_{\mathrm{m} 2}(\mathrm{I}-$ peak $) /{ }^{\circ} \mathrm{C}$ & 72.1 & 71.5 & 74.4 & 74.6 & 74.6 \\
$\Delta H_{2}(\mathrm{I}) / \mathrm{J} \mathrm{g}^{-1}$ & 1.63 & 1.27 & 2.29 & 2.66 & 3.01 \\
$T_{\mathrm{m} 2}(\mathrm{II}-\mathrm{peak}) /{ }^{\circ} \mathrm{C}$ & 175.0 & 182.0 & 155.8 & 144.3 & 133.2 \\
$\Delta H_{2}(\mathrm{II}) / \mathrm{J} \mathrm{g}^{-1}$ & 2.60 & 8.60 & 8.59 & 7.01 & 5.48 \\
$T_{\mathrm{m} 2}\left(\mathrm{III}-\right.$ peak $^{\circ} /{ }^{\circ} \mathrm{C}$ & 197.7 & 193.3 & 204.2 & - & - \\
$\Delta H_{2}(\mathrm{III}) / \mathrm{J} \mathrm{g}^{-1}$ & 14.25 & 6.00 & 0.27 & - & - \\
$T_{\mathrm{m} 2}(\mathrm{IV}-$ peak $) /{ }^{\circ} \mathrm{C}$ & - & - & - & 229.2 & 239.7 \\
$\Delta H_{2}(\mathrm{IV}) / \mathrm{J} \mathrm{g} \mathrm{g}^{-1}$ & - & - & - & 2.30 & 1.95 \\
\hline${ }^{1}$ & & - & & &
\end{tabular}

* The subscripts 1 and 2 correspond to soft and hard segments, respectively.

$T_{\mathrm{g} 1}$ is a measure of relative purity of the soft segment regions. The more soft segment domains are contaminated with dissolved hard segments of high glass transition temperature, the higher is $T_{\mathrm{g} 1}$. The degree of hard segment mixing into soft segment domain depends on the overall hard segment content, both segment lengths, and the affinity of one segment toward the other. The soft segment $T_{\mathrm{g} 1}$ is influenced by restricted movement imposed at the hard segment junction.

The remaining regions of DSC thermal curves result from endotherms associated with hard segment domains. The endotherm of region-I around $55-80^{\circ} \mathrm{C}\left(T_{\mathrm{m} 2}(\mathrm{I})\right.$, denoted region-I) results from breakup of short range order of hard segment induced by room temperature annealing. ${ }^{9}$ The endotherm around $100-180^{\circ} \mathrm{C}\left(T_{\mathrm{m} 2}(\mathrm{II})\right.$, denoted region-II) corresponds to the breakup of long range order of hard segments. The endotherm around $190-220^{\circ} \mathrm{C}$ corresponds to the melting of microcrystalline hard segment $\left(T_{\mathrm{m} 2}(\mathrm{III})\right.$, denoted Region III). The endotherm appears above $220^{\circ} \mathrm{C}\left(T_{\mathrm{m} 2}(\mathrm{IV})\right.$, denoted Region IV) corresponds to the dissociation of $\mathrm{H}$-bond of hard segments bonded near the triol crosslinker.

As indicated in Figure 1 and Table II, the soft segment glass transition temperature $\left(T_{\mathrm{g} 1}\right)$ increased with the concentration of glycerol. Thus polyurethane (PU)-1 had the lowest $T_{\mathrm{g} 1}$ and PU-5 had the highest $T_{\mathrm{g} 1}$ indicating the highest degree of phase segregation for PU-1 and 
lowest degree of phase segregation for PU-5. ${ }^{32}$ When there are hard segments dispersed in the soft domains, $T_{\mathrm{g} 1}$ rises. The dispersion of hard segments in the soft domain increased with the content of glycerol crosslinker. The other reason for increase in $T_{\mathrm{g} 1}$ with glycerol content may be the lower mobility of soft segments with increasing chemical crosslinks.

The endotherm of region-I around $55-80^{\circ} \mathrm{C}$ corresponds to the melting of the short range continuous ordering of hard segment domain induced by annealing at room temperature. ${ }^{32}$ Comparing the DSC data of PU-1-PU-5, we found that the introducing of glycerol in the hard segment decreased $\Delta H_{2}$ (I) at molar ratio of glycerol/MDI lower than $0.05 / 2.3$. However at molar ratio of glycerol/MDI higher than $0.05 / 2.3, \Delta H_{2}(\mathrm{I})$ increased with the content of glycerol. The introducing of glycerol caused the disruption of $\mathrm{H}$-bond of short range ordering of hard segment domain when the molar ratio of glycerol/MDI was lower than $0.05 / 2.3$. At higher glycerol content, $\Delta \mathrm{H}_{2}(\mathrm{I})$ increased with glycerol content, indicating the number of short range ordering hard segment domain increased with glycerol content due to breakup of $\mathrm{H}$-bond of long range ordering and microcrystalline of hard segment domain into short range ordering domain by introducing the glycerol crosslinker into the hard segment.

Only PU-1 and PU-2 have dominant microcrystalline melting endotherms, i.e., $T_{\mathrm{m} 2}$ (III). A very small melting endotherm, i.e., $T_{\mathrm{m} 2}$ (III), is observed in DSC curve of PU-3. DSC data of PU-1 and PU-2 showed the increase in glycerol content of the hard segment to decrease melting temperature $T_{\mathrm{m} 2}$ (III) and heat of fusion $\Delta H_{2}$ (III). However, melting endotherm $\Delta H_{2}$ (II) and peak temperature $T_{\mathrm{m} 2}$ (II) of long range order of hard segment increased with increasing glycerol content at molar ratio of glycerol/MDI below $0.05 / 2.3$. At molar ratio of glycerol/MDI higher than $0.05 / 2.3$, no melting endotherm of $T_{\mathrm{m} 2}$ (III) of micro-crystalline hard segment was observed for PU-4 and PU-5. The endotherm of $T_{\mathrm{m} 2}$ (II) for the breakup of long range order of hard segment domain was much lower for PU-3-PU-5 than those of PU-1 and PU-2. The peak became broader and $T_{\mathrm{m} 2}(\mathrm{II})$ and $\Delta \mathrm{H}_{2}$ (II) decreased in sequential order from PU-3 to PU-5. The presence of glycerol may thus reduce the ordering of hard segment domains.

The physical meaning of the endotherm appears at temperature higher than $220^{\circ} \mathrm{C}$ for PU-4 and PU-5 is still not clear to us. This may be due to dissociation of $\mathrm{H}$-bond of hard segments bonded near the triol crosslinker. Owing to the restriction of chemical crosslinks, the hard segments near the crosslinks have less mobility than those far from crosslinker. Thus $\mathrm{H}$-bonds dissociate at a higher temperature. We studied the annealing behavior of PU-4 and PU-5. ${ }^{33}$ PU samples were melted at $230^{\circ} \mathrm{C}$ for $5 \mathrm{~min}$ then quenched to an annealing temperature between $90-150^{\circ} \mathrm{C}$ and the DSC curves were obtained at various aging times. We found that the endotherm of $T_{\mathrm{m} 2}(\mathrm{IV})$ disappeared after the samples were melted and quenched to the annealing temperature. The peak temperatures and peak areas of $T_{\mathrm{m} 2}$ (II) and $T_{\mathrm{m} 2}$ (III) increased with annealing temperature and time and merged together at higher annealing temperature. The endotherm of $T_{\mathrm{m} 2}$ (IV) was not observed even
Table III. SAXS lamellar repeat distances of polyurethanes

\begin{tabular}{cccc}
\hline Polyurethane & $\begin{array}{c}L / \mathrm{nm} \\
\left.\text { (from } I q^{2}\right)\end{array}$ & $\begin{array}{c}L_{1 \mathrm{D}} / \mathrm{nm} \\
\left.\text { (from } \gamma_{1 \mathrm{D}}\right)\end{array}$ & $\begin{array}{c}Q \\
\text { (arbitrary }\end{array}$ \\
\hline PUit $\times 10^{20} \mathrm{~cm}^{-1}$ ) \\
\hline PU-2 & 15.6 & 14.1 & 1.67 \\
PU-3 & 14.0 & 13.1 & 1.97 \\
PU-4 & 7.3 & 7.7 & 1.05 \\
PU-5 & 8.1 & 7.7 & 0.88 \\
& 9.3 & 8.1 & 0.99 \\
\hline
\end{tabular}

when the samples were annealed at $150^{\circ} \mathrm{C}$ for two days. These results suggest that the hard segments corresponding to $T_{\mathrm{m} 2}(\mathrm{IV})$ may have steric hindrance structures. Melting the crosslinked PU samples at $230^{\circ} \mathrm{C}$ causes increase in the mobility of the hard segments. Thus $\mathrm{H}$-bond of hard segments near the triol crosslinker dissociates and these hard segments move into the microcrystalline domain during quenching and annealing between 120 and $150^{\circ} \mathrm{C}$. Thus the domain size of microcrystalline increases with annealing temperature and annealing time.

\section{SAXS Study}

The small angle X-ray scattering shows the scattering intensity as a function of the angle measured with respect to the direction of the incident X-ray beam. The scattering intensity arises due to local heterogenities in the electron density of the material. For a two-phase system, the invariant quantity $Q$ of overall mean square electron density fluctuation is obtained by integrating $I(q) q^{2}$ all over the scattering angles.

$$
Q=\frac{1}{2 \pi} \int_{0}^{\infty} I(q) q^{2} \mathrm{~d} q
$$

with

$$
q=\frac{4 \pi}{\lambda} \sin (\theta / 2)
$$

where $q$ is the scattering vector, $\theta$ the scattering angle, $\lambda$ the wavelength, and $I(q)$ the scattering intensity at the scattering vector $q$. Typical SAXS intensity profiles $\left(I(q) q^{2} v s . q\right)$ for polyurethanes with various contents of glycerol in hard segments are shown in Figure 2. All exhibit a single scattering maximum indicative of a hard segment inter-domain repeat distance. The invariant $Q$ describes the electron density fluctuation of polymer and is a good approximation to estimate the overall degree of phase separation in segmented polyurethane. $Q$ for these crosslinked polyurethanes are summarized in Table III. As shown in Table III, $Q$ increased from PU-1 to PU-2, then decreased from PU-2 to PU-5 indicating that the introducing of a lower content of glycerol in the hard segment increased phase separation (PU-1-PU-2). At molar ratio glycerol/MDI higher than $0.05 / 2.3$ (PU3-PU-5), the introducing of glycerol increased the degree of mixing of hard- and soft-segments.

The interdomain spacing, $L$, can be estimated from $q_{\mathrm{m}}$ corresponding to the maximum of $I(q) q^{2} v s . q$ curves (Figure 2) using Bragg's equation:

$$
L=2 \pi / q_{\mathrm{m}}
$$

For systems with lamellar structures, one-dimensional 


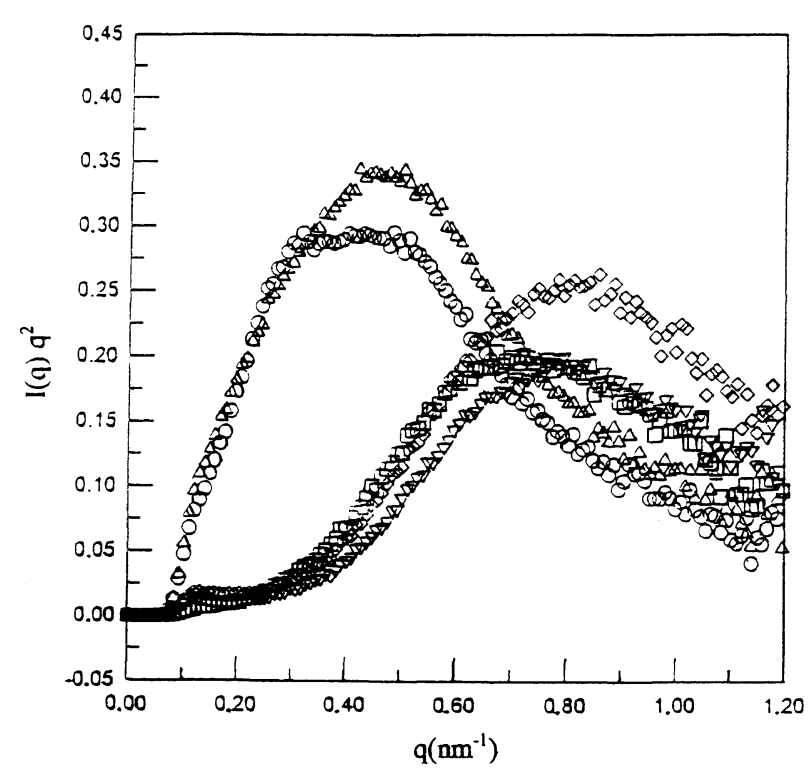

Figure 2. SAXS intensity profiles $I(q) q^{2}$ vs. $q$ curves of crosslinked polyurethanes. $(\bigcirc)$ PU-1; $(\triangle)$ PU-2; $(\diamond)$ PU-3; $(\nabla)$ PU-4; $(\square)$ PU-5.

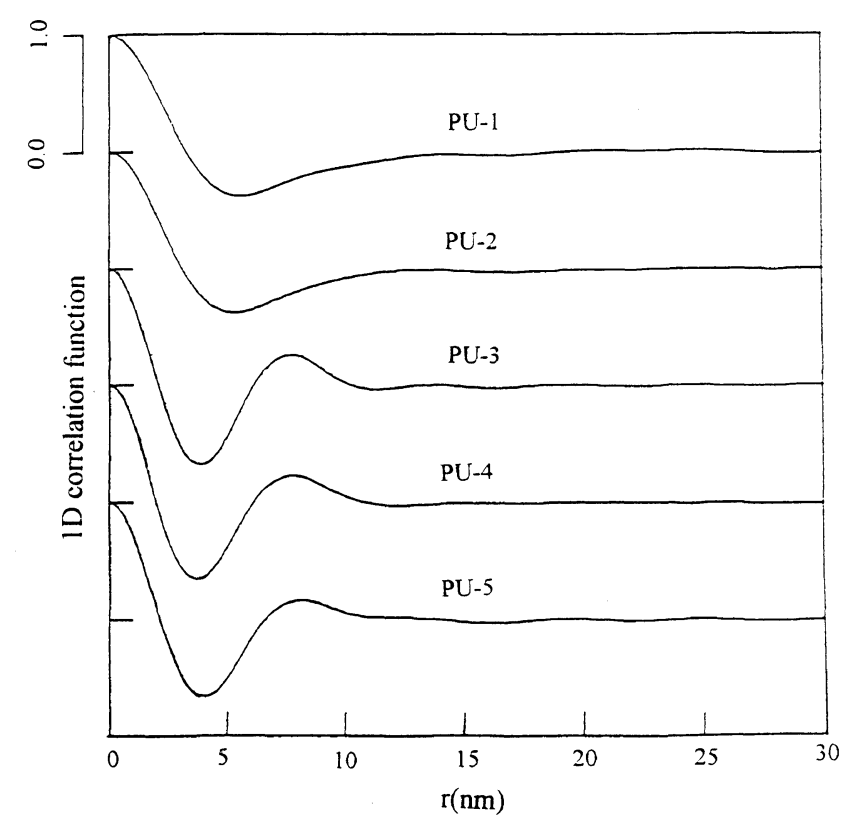

Figure 3. Correlation functions $\gamma_{1}(r)$ vs. $r$ of crosslinked polyurethanes.

correlation function $\gamma_{1}(r)$ has a local maximum at a position $r$ which corresponds to the inter-lamellar repeat distance, $L_{1 \mathrm{D}}$. The one-dimensional correlation function is shown as following:

$$
\gamma_{1}(r)=\frac{1}{Q} \int I(q) q^{2} \cos (q r) \mathrm{d} q
$$

The inter-domain repeat distance, $L$ or $L_{1 \mathrm{D}}$, may be calculated from the data by application of Bragg's law or correlation function analysis. $L$ calculated from eq 3 are listed in Table III. Typical correlation functions $\gamma_{1}(r)$ for crosslinked polyurethanes are shown in Figure 3. The periodicity is estimated from the position of the first subsidiary maximum in the correlation functions. The inter-domain repeat distances, $L_{1 \mathrm{D}}$, estimated from $\gamma_{1}(r)$ are listed in Table III. The inter-domain repeat distance decreased from PU-1 to PU-3 with increasing glycerol crosslinker content in the hard segments. But, at molar ratio of glycerol/MDI higher than $0.1 / 2.3, L$ and $L_{1 \mathrm{D}}$ increased slightly with glycerol crosslinker content.

According to Debye-Bueche theory, ${ }^{34}$ the scattering intensity $I(q)$ is related to inhomogeneity length, $l_{\mathrm{p}}$, and mean square electron density fluctuation, $\left\langle\eta^{2}\right\rangle$, through eq 5 as the scattering vector $q$ is extrapolated to 0 .

$$
\lim _{q \rightarrow 0} I(q)=\lim _{q \rightarrow 0} \frac{8 \pi\left\langle\eta^{2}\right\rangle l_{\mathrm{p}}^{3}}{\left(1+l_{\mathrm{p}}^{2} q^{2}\right)^{2}}+I_{\mathrm{b}}
$$

where $I_{\mathrm{b}}$ is the background intensity.

Extrapolation of the scattering intensity to an infinite scattering vector allows us to calculate Porod's law constant $K_{\mathrm{p}}{ }^{35,36}$ :

$$
\lim _{q \rightarrow \infty} I(q)=\lim _{q \rightarrow \infty}\left(K_{\mathrm{p}} / q^{4}\right) \exp \left(-\sigma^{2} q^{2}\right)+I_{\mathrm{b}}
$$

where $\sigma$ is the inter-facial boundary thickness parameter. Porod's law constant, $K_{\mathrm{p}}$, is related to the ratio of interface surface-to-volume ratio, $S / V$, by the relation:

$$
K_{\mathrm{p}}=2 \pi i_{\mathrm{e}}\left\langle\eta^{2}\right\rangle(S / V)
$$

where $i_{\mathrm{e}}$ is Thompson scattering factor for a single electron. Porod constant, $K_{\mathrm{p}}$, can be used to determine $S / V$ using eq 7 . An equivalent thickness, $E$, for an interphase gradient is given by:

$$
E=12^{1 / 2} \sigma
$$

Rearranging eq 5 , we obtain eq 9 :

$$
\left[I(q)-I_{\mathrm{b}}\right]^{-1 / 2}=\left(8 \pi\left\langle\eta^{2}\right\rangle l_{\mathrm{p}}^{3}\right)^{-1 / 2}\left(1+l_{\mathrm{p}}^{2} q^{2}\right)
$$

$\left\langle\eta^{2}\right\rangle$ and $l_{\mathrm{p}}$ can be obtained from the slope and intercept of a plot of left hand side of eq 9 against $q^{2}$ as $q \rightarrow 0$. Similarly, rearranging eq 6 , we obtained eq 10 :

$$
\ln \left[\left(I(q)-I_{\mathrm{b}}\right) q^{4}\right]=\ln K_{\mathrm{p}}-\sigma^{2} q^{2}
$$

$\sigma$ and $K_{\mathrm{p}}$ can be obtained from the slope and intercept, respectively, of a plot of left hand side of eq 10 against $q^{2}$ as $q \rightarrow \infty$.

Since, $I(q)$ data at high $q$ were noisy, it was hard to obtain $I_{\mathrm{b}}$. In this study, we simulated $I(q)$ data at $q \rightarrow 0$ and $q \rightarrow \infty$ by using eq 5 and 6 , respectively, with a nonlinear least square method. By adjusting the difference between $I_{\mathrm{b}}$ data obtained from eq 5 and eq 6 to be less than $3 \%$, we obtained parameters $\left\langle\eta^{2}\right\rangle, l_{\mathrm{p}}, K_{\mathrm{p}}$, and $\sigma$.

Simulated $\left\langle\eta^{2}\right\rangle, l_{\mathrm{p}}$ (eq 5), $K_{\mathrm{p}}, S / V, \sigma$ (eq 6 and 7), and $I_{\mathrm{b}}$ for these crosslinked polyurethanes are summarized in Table IV. Typical plots of eq 9 and 10 of SAXS data at $q \rightarrow 0$ and $q \rightarrow \infty$ respectively together with simulated results are shown in Figures 4 and 5, respectively. SAXS data revealed that $L, L_{1 \mathrm{D}},\left\langle\eta^{2}\right\rangle$, and $\sigma$ decreased from PU-1 to PU-4 then increased from PU-4 to PU-5 with increasing glycerol content. $l_{\mathrm{p}}$ and $S / V$ increased from PU-1 to PU-4 and then decreased from PU-4 to PU-5 with increasing glycerol content.

\section{Discussion}

From DSC and SAXS, it is obvious that the introducing of glycerol into hard segments strongly affects the morphology of polyurethanes. Since the $-\mathrm{OH}$ 


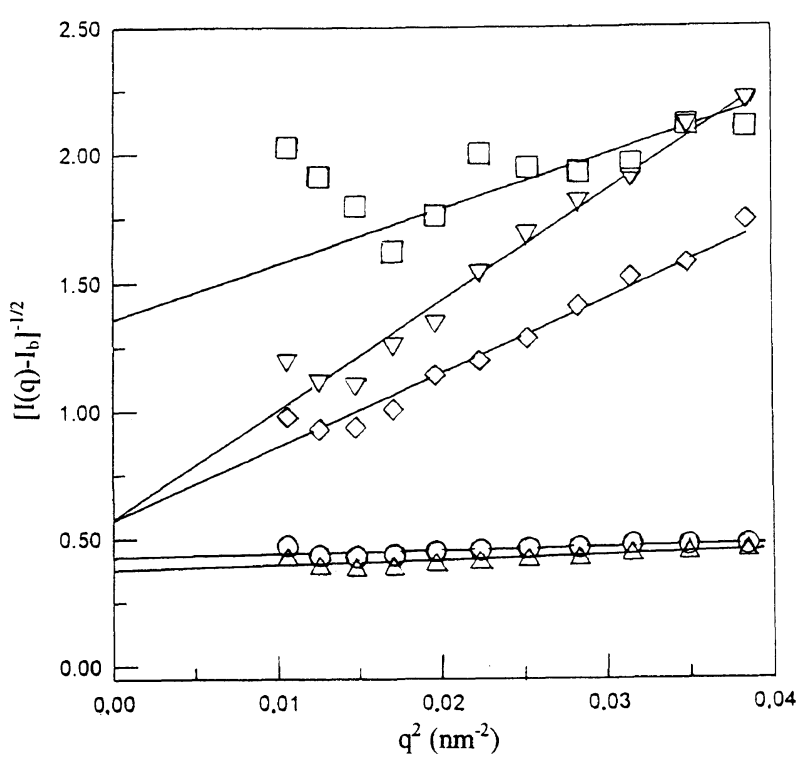

Figure 4. Plots of $\left[I(q)-I_{\mathrm{b}}\right]^{-1 / 2}$ vs. $q^{2}$ at $q \rightarrow 0$ for polyurethanes annealed at room temperature. Full lines are simulated results. $(O)$ PU-1; $(\triangle)$ PU-2; $(\diamond)$ PU-3; $(\nabla)$ PU-4; $(\square)$ PU-5.

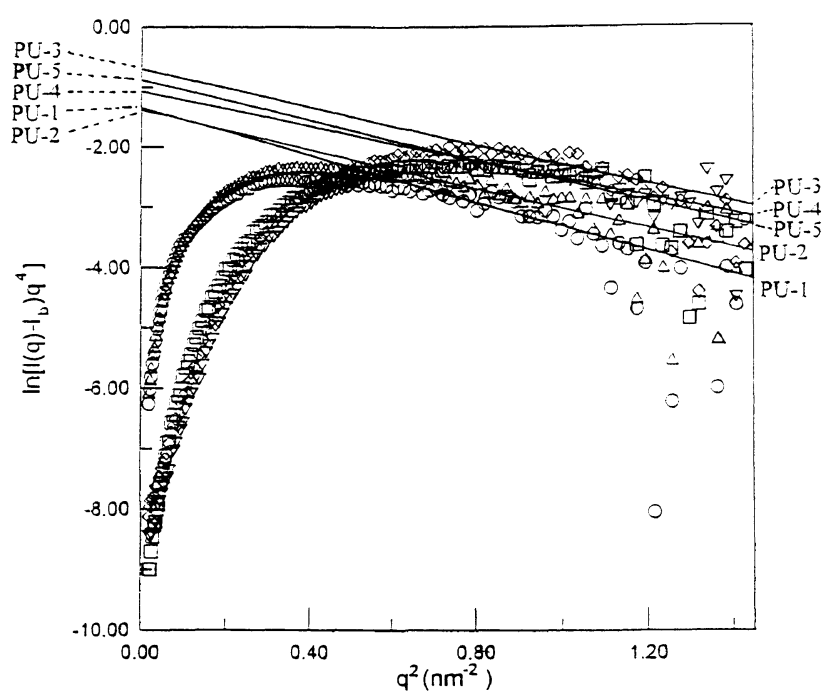

Figure 5. Plots of $\ln \left[\left(I(q)-I_{\mathrm{b}}\right) q^{4}\right]$ vs. $q^{2}$ at $q \rightarrow \infty$ for polyurethanes annealed at room temperature. Full lines are simulated results. $(O)$ PU-1; $(\triangle)$ PU-2; $(\diamond)$ PU-3; $(\nabla)$ PU-4; $(\square)$ PU-5.

equivalent weight of 1,4 -butanediol is higher than that of glycerol, replacing of 1,4-butanediol chain extender with glycerol increased the weight fraction of MDI in PU and thus increased the electron density of PU. The presence of triol functional group also caused higher local MDI concentration near the crosslinking agent than the diol chain extender. However, owing to steric hindrance and the restriction of hard segment mobility of the chemical crosslink, the presence of triol crosslinking agent in the hard segment decreased hard segment $\mathrm{H}$ bond formation.

$T_{\mathrm{m} 2}$ of the melting endotherm corresponds to the domain size of the ordering hard segments aggregated through $\mathrm{H}$-bond. $T_{\mathrm{m} 2}$ increased with the size of hard segment domain formed through $\mathrm{H}$-bonding. The melting enthalpy $\Delta H_{2}$ is proportional to hard segment $\mathrm{H}$-bonding, and thus proportional to the size and number

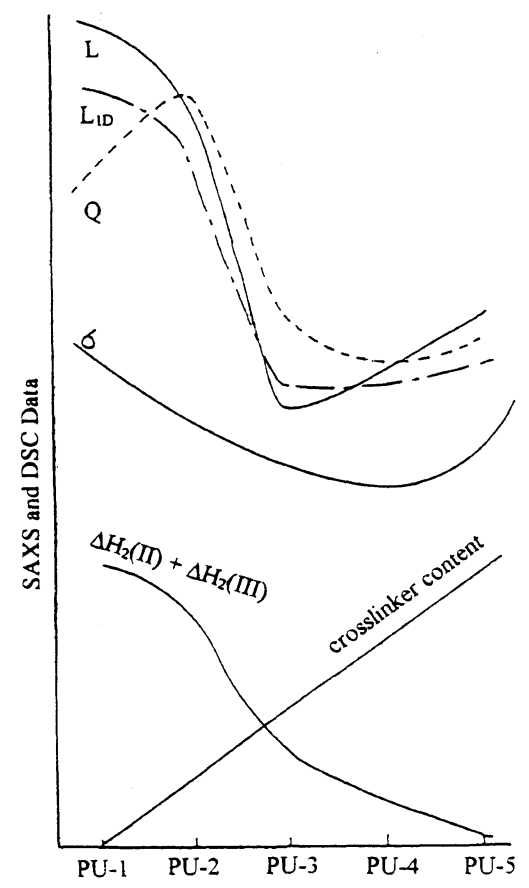

Figure 6. Variation in SAXS parameters and DSC melting enthalpy $\Delta H_{2}($ II $)+\Delta H_{2}$ (III) vs. crosslinker concentration.

of ordering hard segment domains. Figure 6 plots the variation of SAXS parameters, i.e., $Q, L, L_{1 \mathrm{D}}$, and $\sigma$, and melting enthalpy of hard segment, i.e., $\Delta H_{2}$ (III)+ $\Delta H_{2}(\mathrm{II})$, with crosslinker concentration. The aggregation of hard segments in polyurethanes was controlled by: (1) chemical reactions of MDI with chain extender (i.e., 1,4 butanediol) and crosslinking agent (i.e., glycerol) through covalent bond; and (2) H-bond formation between the hard segments. The replacing of 1,4-butanediol with glycerol increased hard segments aggregation through chemical covalent bonds and decreased hard segment aggregation through $\mathrm{H}$-bond formation due to steric hindrance of triol crosslink. $Q, L, L_{1 \mathrm{D}}$, and $\sigma$ are the compromised results of chemical crosslinking covalent bond content and degree of hard segment $\mathrm{H}$ bond formation.

As shown in Figure 6, $Q$ increased from PU-1 to PU-2, and then decreased from PU-2 to PU-4, and finally increased from PU-4 to PU-5. Since replacing 1,4butanediol with glycerol in the hard segment increased MDI content, hence PU-2 had higher $Q$ than PU-1. Decrease of $\mathrm{Q}$ from PU-2 to PU-4 was due to sharp decrease of $\mathrm{H}$-bond formation among the hard segments as glycerol content increased $\left(\Delta H_{2}\right.$ decreased dramatically from PU-2 to PU-4 as indicated by DSC data). Q from PU-4 to PU-5 was similar to that of PU-1 to PU-2. DSC data show that $\Delta H_{2}$ decreased slowly from PU-4 to PU-5, indicating slight decrease of $\mathrm{H}$-bonding formation among hard segments. The effects on electron density fluctuation due to increase of MDI content by substitution of 1,4-butanediol with glycerol and the aggregation of hard segments through crosslink covalent bonding were greater than due to decrease of hard segment $\mathrm{H}$-bond formation and thus $\mathrm{Q}$ increased from PU-4 to PU-5.

On comparing the inter-domain repeat distance $L$ (or $L_{1 \mathrm{D}}$ ) of PU-1 with PU-2 and PU-3, $L$ (or $L_{1 \mathrm{D}}$ ) decreas- 
Table IV. SAXS interfacial parameters for diffuse boundary thickness of polyurethanes

\begin{tabular}{|c|c|c|c|c|c|c|}
\hline Polyurethane & $\begin{array}{c}\left\langle\eta^{2}\right\rangle \\
\times 10^{18} \mathrm{~cm}^{-4}\end{array}$ & $\begin{array}{c}K_{\mathrm{p}} \\
\times 10^{27} \mathrm{~cm}^{-5}\end{array}$ & $\begin{array}{c}S / V \\
\times 10^{8} \mathrm{~cm}^{-1}\end{array}$ & $\frac{\sigma}{\mathrm{nm}}$ & $\frac{l_{\mathrm{p}}}{\mathrm{nm}}$ & $\frac{I_{\mathrm{b}}}{\mathrm{cm}^{-1}}$ \\
\hline PU-2 & 23.0 & 2.47 & 1.89 & 1.27 & 2.27 & 0.0562 \\
\hline PU-3 & 0.340 & 5.04 & 95.9 & 1.26 & 7.11 & 0.101 \\
\hline PU-4 & 0.188 & 3.46 & 116.0 & 1.20 & 8.61 & 0.0671 \\
\hline
\end{tabular}

ed slightly from PU-1 to PU-2 and then decreased dramatically from PU-2 to PU-3 with increasing glycerol content. DSC data show that the melting endotherms $T_{\mathrm{m} 2}(\mathrm{III})$ and $T_{\mathrm{m} 2}$ (II) of PU-1 and PU-2 were much higher than the $T_{\mathrm{m} 2}$ (II) of PU-3 indicating PU-1 and PU-2 had larger ordering hard segment domain size formed through $\mathrm{H}$-bonds and thus had longer inter-domain repeat distance $L$ (or $L_{1 \mathrm{D}}$ ) than PU-3. The lower $T_{\mathrm{m} 2}$ (II) and higher $\mathrm{\Delta H}_{2}$ (I) of PU-3 than those of PU-1 and PU-2 suggest that the size of ordering hard segment domains was smaller but the number of ordering hard segment domain particles was higher for PU-3 than for PU-1 and PU-2. Many small ordering hard segment particles may thus be dispersed in the soft domain of PU-3. Thus a shorter inter-domain repeat distance $L$ (or $L_{1 \mathrm{D}}$ ) was observed for PU-3. As the glycerol content increased from PU-3 to PU-5, the $\Delta H_{2}$ (II) and $T_{\mathrm{m} 2}$ (II) decreased with increasing crosslinking agent content suggesting the number and size of ordering hard segment particles decreased with increasing glycerol content. Thus $L$ increased slightly from PU-3 to PU-5.

For an ideal two phase system with sharp phase separation, a Porod's plot of $\ln \left[\left(I(q)-I_{\mathrm{b}}\right) q^{4}\right] v s . q^{2}$ should reach a constant value. ${ }^{37}$ In most real systems, plots $\ln \left[\left(I(q)-I_{\mathrm{b}}\right) q^{4}\right]$ do not reach a constant value at high angles. The factors including thermal density fluctuations and isolated mixing of one type of segment in the other (intra-domain mixing) would result in a positive slope (i.e., negative $\sigma$ value) in the Porod plot (Figure 5 ). If any variable causes reduction in the intensity at high angles, a negative slope (i.e., positive $\sigma$ value) of Porod plot would result. The presence of diffuse phase boundaries would cause a negative slope of Porod's plot to occur because they result in larger volume fraction of material having the electron density that is near the mean density of the two phases. If two segmented copolymers are compared where these systems pose identical interfacial boundary thickness but differ in the degree of isolated mixing of hard segments in the soft segment phase, the negative slope of Porod plot (i.e., $\sigma$ value) will be less for the system with higher mixing. ${ }^{37}$ This same material would therefore indicate smaller interfacial boundary thickness. The interfacial surface-to-volume ratio, $S / V$, is also an indicator of the degree of mixing of different phases. $S / V$ increased with the degree of mixing. ${ }^{37}$ In the present work, as shown in Table IV, $S / V$ increased and $\sigma$ decreased from PU-1 to PU-4 then $S / V$ decreased and $\sigma$ increased from PU-4 to PU-5. More and more isolated mixing of hard segments in the soft domain thus possibly occurred as triol crosslinker content increased from PU-1 to PU-4. Though the aggregation of hard segments through tri-functional covalent bonds increased with increasing triol crosslinker content, the steric hindrance of triol crosslinker caused dramatic decrease in the aggregation of hard segments through $\mathrm{H}$-bond formation as the triol crosslinker content increased from PU-1 to PU-4 resulting in increase in the isolated mixing of hard segments in the soft domain and thus an increase in $S / V$ and decrease in $\sigma$ from PU-1 to PU-4. However, the degree of H-bond formation decreased slightly from PU-4 to PU-5 and thus increase in the aggregation of hard segments through trifunctional covalent bond caused decrease in isolated mixing of hard segments in soft segment phase. Hence, $S / V$ decreased and $\sigma$ increased as triol crosslinker content increased from PU-4 to PU-5.

\section{CONCLUSION}

The introduction of glycerol into the polyurethane hard segment for a substitution of 1,4-buatnediol chain extender has strong effect on the morphology of polyurethanes. Owing to lower $\mathrm{OH}$-equivalent weight of glycerol than that of 1,4-butanediol, substitution of 1,4-butanediol with glycerol in the hard segment increased the weight fraction of MDI and decreased hard segment molecular chain length. The triol functional groups of glycerol also led to higher aggregation of hard segments through crosslink covalent bonds. However, highly steric hindrance of glycerol decreased hard segment $\mathrm{H}$-bond formation. The size and number of hard segment ordering domains and degree of hard- and soft-segments mixing are due to the aggregation of hard segments through crosslink covalent bonds and hard segment $\mathrm{H}$-bond formation.

\section{REFERENCES}

1. S. L. Cooper and A. V. Tobolsky, J. Appl. Polym. Soc., 10, 1837 (1966).

2. T. K. Kwei, J. Appl. Polym. Sci., 27, 2891 (1982).

3. D. S. Huh and S. C. Cooper, Polym. Eng. Sci., 11, 369 (1971).

4. C. E. Wilkes and C. S. Yusek, J. Macromol. Sci. Phys., B7, 157 (1973).

5. (a) G. G. Seefried, Jr., J. V. Koleske, and F. E. Critchfield, J. Appl. Polym. Sci., 19, 2493 (1975); (b) ibid., 3185.

6. G. W. Miller and J. H. Saunders, J. Polym. Sci., Port A, 18, 1923 (1970)

7. S. Abouzahr and G. L. Wilkes, J. Appl. Polym. Sci., 29, 2695 (1984).

8. J. A. Miller, S. B. Lin, K. K. S. Hwang, K. S. Wu, P. E. Gibson, and S. L. Cooper, Macromolecules, 18, 32 (1985).

9. R. W. Seymour and S. L. Cooper, Macromolecules, 6, 48 (1973).

10. J. T. Koberstein and T. P. Russell, Macromolecules, 19, 714 (1986).

11. J. T. Koberstein and A. F. Galambos, Macromolecules, 25, 5618 (1992).

12. J. T. Koberstein, A. F. Galambos, and L. M. Leung, 
Macromolecules, 25, 6195 (1992).

13. J. T. Koberstein and L. M. Leung, Macromolecules, 25, 6205 (1992)

14. Y. Li, T. Gao, and B. Chu, Macromolecules, 25, 1737, (1992).

15. Y. Li, T. Gao, J. Liu, K. Linliu, C. R. Desper, and B. Chu, Macromolecules, 25, 7365 (1992)

16. Y. Li, J. Liu, H. Yang, D. Ma, and B. Chu, J. Polym. Sci., Polym. Phys., Ed., 31, 853 (1993).

17. Y. Li, W. Kang, J. O. Staffer, and B. Chu, Macromolecules, 27, $612(1994)$

18. R. J. Goddar and S. L. Cooper, J. Polym. Sci., Polym. Phys. Ed., 32, 1557 (1994)

19. B. P. Grady, E. M. O'Connell, C. Z. Yang, and S. L. Cooper, J. Polym Sci., Polym. Phys. Ed., 32, 2357 (1994).

20. R. J. Goddar and S. L. Cooper, Macromolecules, 28, 1401 (1995).

21. S. C. S. Paik, C. B. Hu, and C. S. Wu, Macromolecules, 13, 111 (1980)

22. J. A. Miller and S. L. Cooper, J. Polym. Sci., Polym. Phys. Ed., 23, 1065 (1985)

23. L. M. Leung and J. T. Koberstein, Macromolecules, 19, 706 (1986).

24. J. T. Koberstein and I. Gancarz, J. Polym. Sci., Polym. Phys.
Ed., 24, 2487 (1986)

25. J. C. West and S. L. Cooper, J. Polym. Sci., Polym. Symp., 60, 27 (1977).

26. M. M. Coleman, K. H. Lee, D. J. Skrovanek, and D. C. Painter, Macromolecules, 19, 2149 (1986).

27. R. J. and S. L. Cooper, Macromolecules, 28, 1390 (1995).

28. H. J. Tao, C. W. Meuse, X. Yang, W. J. MacKnight, and S. L. Hsu, Macromolecules, 27, 7146 (1994).

29. L. A. Gower and D. J. Lyman, J. Polym. Sci., Polym. Chem., Ed., 33, 2257 (1995).

30. G. L. Wilkes, S. L. Samuel, and R. G. Crystal, J. Macromol. Sci.-Phys., B10, 203 (1974).

31. J. Foka and H. Janik, Polym. Eng. Sci., 29, 113 (1989).

32. T. R. Hesketh, J. W. C. van Bogart, and S. L. Cooper, Polym. Eng. Sci., 20, 190 (1980).

33. Y. M. Tsai and T. L. Yu, unpublished data.

34. P. Debye and A. M. Bueche, J. Appl. Phys., 20, 5518 (1949).

35. G. Porod, Kolloid-Z. Z. Polym., 124, 83 (1951).

36. W. Ruland, J. Appl. Crystallogr., 4, 70 (1971).

37. D. Tyagi, J. E. McGrath, and G. L. Wilkes, Polym. Eng. Sci., 26. 1371 (1986). 